\title{
QUALIDADE DE MUDAS DE EUCALIPTO PRODUZIDAS SOB DIFERENTES LÂMINAS DE IRRIGAÇÃO E DOIS TIPOS DE SUBSTRATO ${ }^{1}$
}

\author{
Jane Luísa Wadas Lopes² ${ }^{\text {, Iraê Amaral Guerrini³ e João Carlos Cury Saad }}{ }^{3}$
}

\begin{abstract}
RESUMO - Este trabalho teve por objetivo avaliar lâminas de irrigação na produção de mudas de Eucalyptus grandis, produzidas em dois substratos comerciais à base de cascas de árvores (CPV e CATV). O experimento foi conduzido na Camará - Mudas Florestais, em Ibaté, SP, na estação inverno/primavera/2003, constituindose de um delineamento de blocos ao acaso com quatro repetições, sendo cinco lâminas de irrigação diárias $(6,8,10,12$ e $14 \mathrm{~mm})$, aplicadas através de uma barra de irrigação em diferentes horários (10, 13 e $16 \mathrm{~h})$. Aos 108 dias após a aplicação foram realizadas avaliações da altura de parte aérea, diâmetro de colo, relação altura da parte aérea/diâmetro de colo, número de pares de folhas, matéria seca da parte aérea e das raízes e área foliar. Com relação às características morfológicas, verificou-se a influência das lâminas em todas as variáveis. Dessa maneira, concluiu-se que as lâminas de irrigação de 12 e de $14 \mathrm{~mm} \mathrm{dia}^{-1}$ foram as que mais contribuíram para o desenvolvimento das mudas, com qualidade ótima aos 108 dias após a semeadura.
\end{abstract}

Palavras-chave: Manejo hídrico, substrato e viveiro.

\section{QUALITY OF EUCALYPTUS SEEDLINGS UNDER DIFFERENT DEPTHS OF IRRIGATION AND TWO SUBSTRASTES}

\begin{abstract}
The objective of this work was to evaluate irrigation depths in the production of Eucalyptus grandis seedlings, produced in two commercial substrates containing tree bark (CPV and CATV). The experiments took place in Camará-Mudas Florestais, in Ibaté - São Paulo, from winter to spring/2003, consisting of a randomized blocks design with four replicates, with 5 daily watering (6, 8, 10, 12 and $14 \mathrm{~mm}$ ), applied several times during the day (at $10 \mathrm{am}, 13 \mathrm{pm}$ and $16 \mathrm{pm}$ ). At 108 days after sowing, the following parameters were assessed: height of aerial part, neck diameter, relation height of aerial part / neck diameter, number of leaf pairs, dry matter of the aerial part and roots, and leaf area. Depths of 6 and $8 \mathrm{~mm}$ per day reduced drastically seedling growth. The irrigation depths also influenced all the parameters of morphological characteristics. It was concluded that the water depths as high as 12 and $14 \mathrm{~mm}_{\text {day }}^{-1}$ helped the development of the seedlings, with excellent quality at 108 days after sowing.
\end{abstract}

Keywords: Hydric management, substrate and nursery.

\section{INTRODUÇÃO}

Irrigar com eficiência em recipientes pequenos chega a ser um grande desafio. Tubetes apresentam particularidades quando comparados com o cultivo em solos, devido à maior frequiência de irrigação que se dá em função do baixo volume de substrato disponível para a planta. Isso faz que se deva ter, maior controle da irrigação, prevenindo o estresse hídrico na fase de crescimento (WENDLING e GATTO, 2002). Para esses autores, a freqüência e o volume de água devem ser determinados conforme o substrato a ser usado.

\footnotetext{
${ }^{1}$ Recebido em 09.10.2006 e aceito para publicação em 24.01.2007.

${ }^{2}$ Programa de Pós-Graduação em Agronomia da UNESP/FCA. Departamento de Engenharia Rural, Cx. P. 237, 18603-970 Botucatu-SP. E-mail: <jane.lopes@ terra.com.br>.

${ }_{3}^{3}$ Departamento de Engenharia Rural da UNESP/FCA. Cx. P. 237, 18603-970 Botucatu-SP. E-mail: <iguerrini@ fca.unesp.br>; joaosaad@fca.unesp.br>.
} 
Alvarenga et al.(1994) estudou em E. grandis, dois níveis de umidade no solo, sendo um na capacidade de campo e outro a -1,5 MPa, verificando melhores resultados nas características morfológicas quando as plantas eram mantidas na capacidade de campo. Chaves et al. (2004) realizaram estudos com clones de eucalipto produzidos em tubetes de aproximadamente $60 \mathrm{~mL}$ para plantios em solos com disponibilidade hídrica diferenciada (um na capacidade de campo e outro somente após serem detectados visualmente na planta os sintomas de murcha), verificando que os clones apresentaram diferentes adaptações nos ambientes com variabilidade de água. Silva et al. (2004) avaliaram as características morfofisiológicas de mudas de $E$. grandis sob condições hídricas diferenciadas (-0,05 e -1,5 MPa), obtendo resultados não diferenciados em função do regime hídrico da maior parte das características. Lopes et al. (2005) avaliaram os efeitos da irrigação, através da aplicação de cinco lâminas brutas de irrigação, na sobrevivência e nas características fisiológicas de mudas de E. grandis produzidas em diferentes substratos, verificando que o regime hídrico influenciou essas características.

Gervásio (2003) garantiu ótima distribuição de água com uniformidades acima de $90 \%$, com uma barra do tipo "pulverização agrícola" na irrigação de mudas de cafeeiro.

Substratos com menor capacidade de retenção de água (casca de arroz carbonizada, areia etc.) requerem irrigações mais freqüentes que os de maior capacidade de retenção (turfas, compostos orgânicos, fibras de coco etc.). Para Costa (2003), o substrato deve garantir o suprimento de oxigênio para o sistema radicular, a nutrição requerida pelas plantas e o controle fitossanitário, bem como evitar os problemas de salinidade. Milner (2002) apud Lopes (2004) sugere que seja usado um fator chamado de "taxa de lixiviação", que é um porcentual de água a mais no momento da irrigação, para prevenir o acúmulo de sais.

Assim, o objetivo deste trabalho foi testar, em substratos à base de cascas de árvores, a melhor lâmina de irrigação diária, para a garantia da melhor qualidade de mudas de Eucalyptus grandis em menor período vegetativo.

\section{MATERIAL E MÉTODOS}

Os ensaios experimentais de viveiro foram desenvolvidos no período de junho a outubro de 2003 na Camará - Mudas Florestais, em Ibaté, SP.

\section{R. Árvore, Viçosa-MG, v.31, n.5, p.835-843, 2007}

Sementes de E. grandis de pomar de sementes clonal foram semeadas em tubetes de $50 \mathrm{~cm}^{3}$, em dois substratos comerciais: CPV-constituído de casca de pinus e vermiculita e CATV-constituído de cascas de pinus, carvão, turfa e vermiculita. Aos 50 dias após a semeadura (DAS), as plantas foram divididas em lotes. Foram separadas e medidas 1.600 plantas (do grupo das médias e maiores) de cada substrato, para compor a área útil (cada repetição continha 80 plantas úteis), e 680 plantas (de cada substrato) para compor a bordadura (dupla), com altura e diâmetros equivalentes, que foram alternadas ocupando área de $49 \mathrm{~cm}^{2}$ cada uma. Foram definidas cinco lâminas de irrigação diária $(6,8,10$, 12 e $14 \mathrm{~mm}$ ), e para cada uma foi formado um canteiro longitudinal, com as plantas divididas em blocos, com quatro repetições. O número de passadas da barra na extensão do canteiro definiu a lâmina bruta de irrigação aplicada.

Como adubação de base foi usada a formulação 15:10:10 de adubo de liberação lenta e realizada uma mistura homogênea com $4 \mathrm{~kg}$ para cada $\mathrm{m}^{3}$ de substrato. Foram realizadas duas adubações de cobertura: na primeira, aos $85 \mathrm{DAS}$, usaram-se $3,0 \mathrm{~g} \mathrm{~L}^{-1}$ de nitrato de cálcio, 1, $0 \mathrm{~g} \mathrm{~L}^{-1}$ de sulfato de amônia, 1,0 $\mathrm{g} \mathrm{L}^{-1} \mathrm{de}$ nitrato de potássio e $1,2 \mathrm{~g} \mathrm{~L}^{-1}$ de sulfato de magnésio; na segunda, aos $100 \mathrm{DAS}$, usou-se $0,690 \mathrm{~g} \mathrm{~L}^{-1}$ de potássio, cuja fonte foi $\mathrm{KCl}$ (cloreto de potássio e $0,418 \mathrm{~g} \mathrm{~L}^{-1} \mathrm{de}$ cálcio, cuja fonte foi $\mathrm{CaCl}$ (cloreto de cálcio).

No viveiro foram realizados os testes preliminares com barras de irrigação (para a determinação da vazão necessária e tempo de deslocamento). Na Faculdade de Ciências Agronômicas da UNESP foram realizadas as análises morfológicas das plantas e físico-químicas do substrato.

A partir da experiência prática de Lopes (2004), foi definida a frequiência de aplicação em três horários ao longo do dia (10, 13 e 16 horas), com distribuição nos canteiros da seguinte maneira: $6 \mathrm{~mm}$ : 2,0 mm às $10 \mathrm{~h}, 13 \mathrm{~h}, 16 \mathrm{~h} ; 8$ mm: 2,0 mm às $10 \mathrm{~h}$ e $16 \mathrm{~h} ; 4 \mathrm{~mm}$, às $13 \mathrm{~h} ; 10 \mathrm{~mm}$ : 2,0 mm às $10 \mathrm{~h}$ e 4,0 mm às $13 \mathrm{~h}$ e 16 $\mathrm{h}$; $12 \mathrm{~mm}$ : $2,0 \mathrm{~mm}$ às $10 \mathrm{~h}, 4 \mathrm{~mm}$ às $13 \mathrm{~h}$ e $6 \mathrm{~mm}$ às $16 \mathrm{~h}$; e $14 \mathrm{~mm}$ : 2,0 mm às $10 \mathrm{~h}$ e $6 \mathrm{~mm}$ às $13 \mathrm{~h}$ e $16 \mathrm{~h}$.

Foram desprezadas as chuvas de $1 \mathrm{~mm}$ (duas ocasiões). No dia 26 de agosto, nenhum dos canteiros recebeu a irrigação das $10 \mathrm{~h}$, e nos dias 17 e 27 de setembro, quando houve chuvas de 5 e $8 \mathrm{~mm}$, respectivamente, ao longo do dia, não se fez irrigação. 
A determinação das características físicas dos substratos foi realizada de acordo com a metodologia de Carvalho e Silva (1992). Para CPV, a microporosidade foi de $46,56 \%$ e a macroporosidade de $29,94 \%$ (porosidade total de $76,50 \%$ ); e para CATV a microporosidade foi de $53,36 \%$ e a macroporosidade de $25,31 \%$ (porosidade total de 78,67\%), considerados por Gonçalves e Poggiani (1996) como adequados niveis de microporosidade e porosidade total. Para macroporosidade, esses autores citaram valores de $35-45 \%$.

Para a avaliação química dos substratos, foi formada uma amostra composta. As análises foram feitas no Departamento de Recursos Naturais - Ciência do Solo, da Faculdade de Ciências Agronômicas da UNESP. Para determinação dos nutrientes totais, usou-se a metodologia do Laboratório de Análise de Fertilizantes e Corretivos, conforme orientação do Ministério da Agricultura (BRASIL, 1988), enquanto para os disponíveis nos substratos: zinco $(\mathrm{Zn})$, ferro $(\mathrm{Fe})$, manganês $(\mathrm{Mn})$, cobre $(\mathrm{Cu})$, potássio $(\mathrm{K})$, cálcio $(\mathrm{Ca})$ e magnésio $(\mathrm{Mg})$ foi seguido o método descrito por Sonneveld et al. (1990) apud Abreu et al. (2002), na proporção de uma parte de substrato para duas partes de água destilada (1:2). A partir do extrato, foram determinados os teores disponíveis dos nutrientes. Para determinação do potencial de hidrogênio $(\mathrm{pH})$ e da condutividade elétrica (EC), adotou-se a mesma metodologia usada para os nutrientes disponíveis, obtendo as leituras através de um pHmetro e um condutivímetro.

A avaliação das características morfológicas foi realizada aos 108 DAS, utilizando-se 10 plantas de cada repetição. Foram medidos: altura de parte aérea (HPA), diâmetro de colo (DC), área foliar (AF), massa seca de parte aérea (MSA) e de raízes (MSR) e número de pares de folhas (NPF). Foram usados paquímetro digital, régua numerada, balança analítica e medidor de AF (usado para definir a AF e para o ajuste da equação de regressão linear utilizada no cálculo das AF, posterior à digitalização das imagens das folhas).

As determinações iniciaram-se da manhã seguinte ao último dia das irrigações, bem como foram digitalizadas as imagens das folhas, separadas as raízes dos substratos e realizada a secagem dos órgãos da planta, que foi feita em estufa a $60^{\circ} \mathrm{C}$ até a obtenção de massa constante.

\section{RESULTADOS E DISCUSSÃO}

Os resultados apresentados na Tabela 1 indicam que os valores de matéria orgânica dos dois substratos (CPV e CATV) correspondem aos valores citados como ideais para Gonçalves e Poggiani (1996). A relação carbono/nitrogênio (C/N) é considerada elevada para ambos os substratos, em comparação com os dados desses autores, que apresentam como adequadas relações $\mathrm{C} / \mathrm{N}$ de 8 a $12 / 1$. No entanto, não foi verificado nenhum atraso no desenvolvimento inicial das mudas.

Para N, os valores obtidos nesta pesquisa (Tabela 1) estão na mesma faixa encontrada por Silva (2003). Quanto ao $\mathrm{pH}$, Sturion (1981) indica como ideal a faixa de 6,0 a 7,0, o qual permitiria a disponibilidade dos nutrientes, não ocasionando problemas de toxidez pelo excesso de Al e Mn; porém, neste experimento não foram observados problemas.

Tabela 1 - Teores totais de nitrogênio, matéria orgânica e carbono, de $\mathrm{pH}$ e condutividade elétrica e teores disponíveis de macronutrientes e micronutrientes no extrato 1:2 nos substratos, antes da produção das mudas de $E$. grandis

Table 1 - Total nitrogen, organic matter and carbon contents, pH and electrical conductivity and availability of macronutrient and micronutrient contents in the extract 1:2 of the substrates before E. grandis seedling production

\begin{tabular}{lcc}
\hline Nutriente & \multicolumn{2}{c}{ Substrato } \\
\cline { 2 - 3 } & CPV & CATV \\
\hline Nitrogênio $\left(\mathrm{g} \mathrm{kg}^{-1}\right)$ & 1,50 & 0,63 \\
Matéria Orgânica $\left(\mathrm{g} \mathrm{kg}^{-1}\right)$ & 81 & 40 \\
Carbono $\left(\mathrm{g} \mathrm{kg}^{-1}\right)$ & 45 & 22 \\
Relação C:N & $30: 1$ & $35: 1$ \\
pH & 4,1 & 4,8 \\
CE $\left.(\mathrm{mSm})^{-1}\right)$ & 1,08 & 4,26 \\
Fósforo $\left(\mathrm{g} \mathrm{kg}^{-1}\right)$ & 0,0719 & 0,0428 \\
Potássio $\left(\mathrm{g} \mathrm{kg}^{-1}\right)$ & 0,0578 & 0,3008 \\
Magnésio $\left(\mathrm{g} \mathrm{kg}^{-1}\right)$ & 0,1053 & 0,4543 \\
Cálcio $\left(\mathrm{g} \mathrm{kg}^{-1}\right)$ & 0,0071 & 0,4645 \\
Enxofre $\left(\mathrm{g} \mathrm{kg}^{-1}\right)$ & 3,09 & 62,78 \\
Boro $\left(\mathrm{mg} \mathrm{kg}^{-1}\right)$ & 0,014 & 0,0 \\
Ferro $\left(\mathrm{mg} \mathrm{kg}^{-1}\right)$ & 0,30 & 0,07 \\
Manganês $\left(\mathrm{mg} \mathrm{kg}^{-1}\right)$ & 1,21 & 0,13 \\
Cobre $\left(\mathrm{mg} \mathrm{kg}^{-1}\right)$ & 0,24 & 0,06 \\
Zinco $\left(\mathrm{mg} \mathrm{kg}^{-1}\right)$ & 0,09 & 0,01 \\
\hline
\end{tabular}


Para os teores dos nutrientes disponíveis nos substratos (Tabela 1) tem-se que: comparando os níveis ótimos, definidos por Abad et al. (1992) apud Ansorena Miner (1994) de substratos para cultivos, verificouse que o Mg e o Mn estavam na faixa ótima e que o $\mathrm{P}$ se encontrava muito acima do nível ótimo em ambos os substratos (deveria ser entre 6-10 $\mathrm{mg} \mathrm{L}^{-1}$ ); o Fe estava abaixo do nível ótimo no CATV (deveria ser entre $0,3-3,0 \mathrm{mg} \mathrm{L}^{-1}$ ); o Ca se apresentava abaixo do nível ótimo no CPV (deveria ser maior que 200 $\mathrm{mg} \mathrm{L}^{-1}$ ); o B não foi encontrado em CATV (deveria ser entre $\left.0,005-0,5 \mathrm{mg} \mathrm{L}^{-1}\right)$; o $\mathrm{Zn}$ estava abaixo do nível ótimo em ambos (deveria ser entre 0,3 - 3,0 mg $\mathrm{L}^{-1}$ ); e o $\mathrm{K}$ se achava acima da faixa ótima para CATV (300,82 $\mathrm{mg} \mathrm{L}^{-1}$ ) e bem abaixo em CPV (deveria ser entre 150 e $249 \mathrm{mg} \mathrm{L}^{-1}$ ). No entanto, não foram verificados efeitos tóxicos nas plantas.

Houve boa correlação entre as lâminas de irrigação aplicadas e a altura da parte aérea (HPA), pela análise de regressão apresentada na Figura 1, conforme os critérios de Gomes et al. (1996), que estabeleceram valores de 15 a $30 \mathrm{~cm}$ para HPA de E. grandis para plantio. Nesta pesquisa foram verificadas HPA de 26,45 e 24,76 $\mathrm{cm}$ para CPV e CATV, respectivamente, com $10 \mathrm{~mm} \mathrm{dia}^{-}$ ${ }^{1}$. O incremento em altura foi proporcional ao aumento da lâmina. No caso do substrato CATV com lâmina de até $10 \mathrm{~mm} \mathrm{dia}^{-1}$, ocorreu incremento médio de altura em torno de $2 \mathrm{~cm}$; acima desse valor de lâmina, foi de cerca de $3 \mathrm{~cm}$ para cada $\mathrm{mm}$. No caso do CPV, o incremento de altura se manteve praticamente constante (na faixa de $2 \mathrm{~cm}$ para cada $\mathrm{mm}$ ). Considerando os critérios de Gomes et al. (1996) para HPA, o ciclo vegetativo das mudas neste experimento poderia ter sido menor (em torno de 90 dias) do que o avaliado de 108 DAS.

Rawat et al. (1985), trabalhando com E. tereticornis mantido em diferentes umidades do solo, concluíram que o crescimento em altura não foi proporcional ao aumento da umidade. Alvarenga et al. (1994), estudando o efeito de dois níveis de umidade (um na capacidade de campo e outro com potencial de água no solo de - 1,5 $\mathrm{MPa}$ ) em E. grandis, encontraram crescimento superior a $65 \%$ nas plantas produzidas na capacidade de campo.

Gomes et al. (1996) estabeleceram um valor mínimo de diâmetro de colo (DC) de 2 mm e Lopes (2004), de 2,5 mm para plantio de $E$. grandis. Nesta pesquisa foram obtidos 2,19 mm quando se aplicou uma lâmina de irrigação de $6 \mathrm{~mm} \mathrm{dia}^{-1}$ em CPV e de $8 \mathrm{~mm} \mathrm{dia}^{-1}$ em CATV (Figura 2), bem como valores médios de DC maiores do que 2,5 $\mathrm{mm}$ a partir de $8 \mathrm{~mm} \mathrm{dia}^{-1}$ para CPV e a partir de $11 \mathrm{~mm}$ dia $^{-1}$ para CATV. Desse modo, também para o diâmetro de colo o ciclo vegetativo poderia ter sido menor (em torno de 90 dias) que o avaliado de 108 DAS.

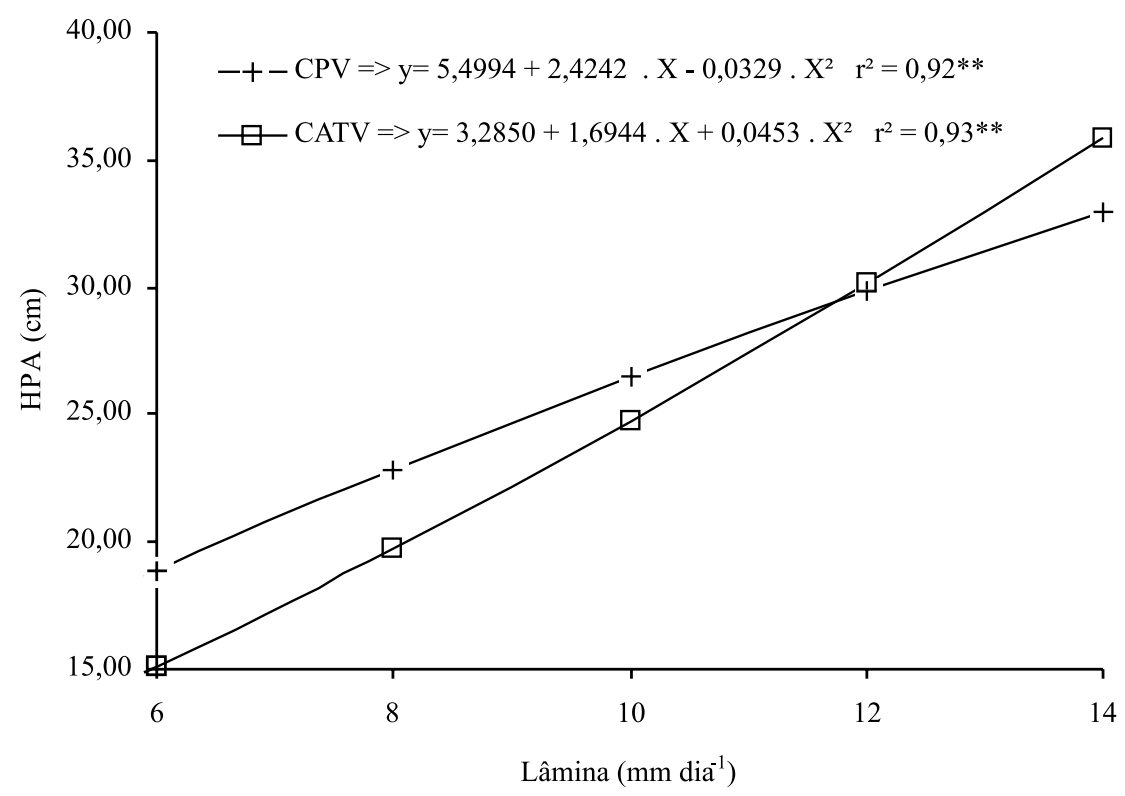

Figura 1 - Altura das mudas de E. grandis ao final do ciclo, sob diferentes lâminas de irrigação. Figure 1 -Height of E. grandis seedlings at the end of the cycle under different irrigation depths.

R. Árvore, Viçosa-MG, v.31, n.5, p.835-843, 2007 


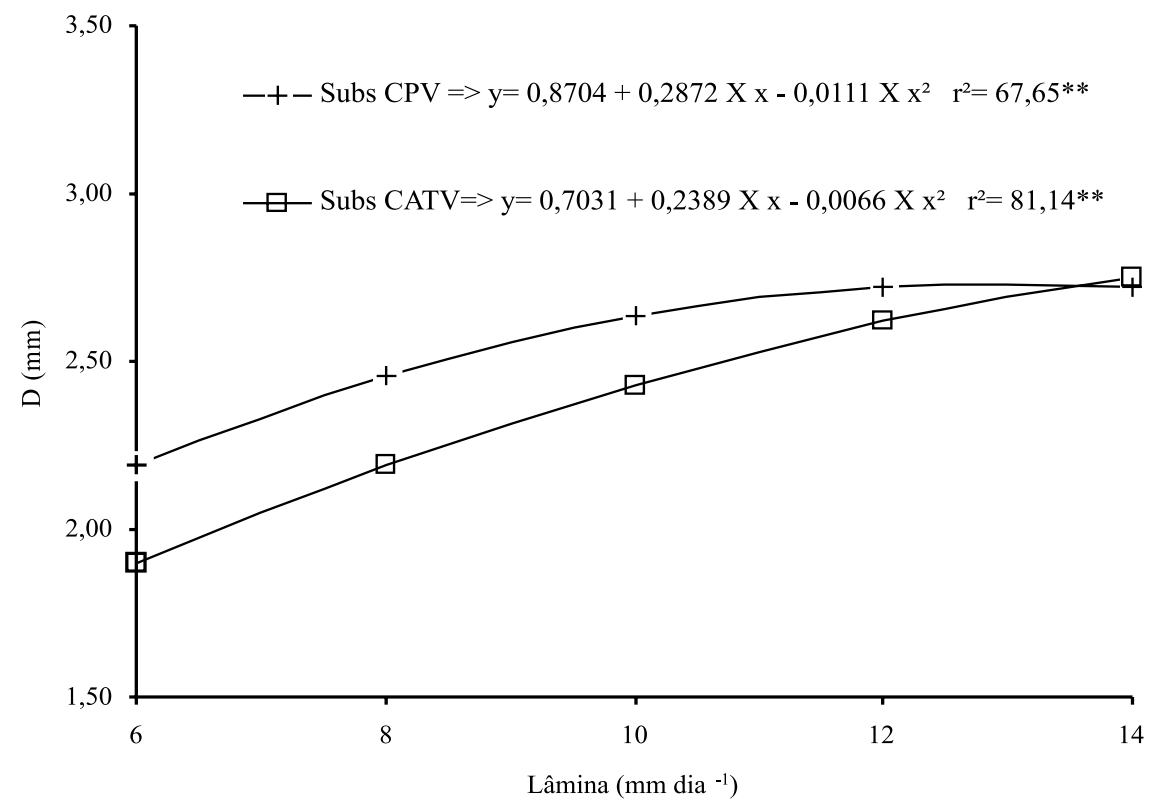

Figura 2 - Diâmetro de colo das mudas de E. grandis, ao final do ciclo, sob diferentes lâminas de irrigação. Figure 2-Neck diameter of E. grandis seedlings of at the end of the cycle under different irrigation depths.

Sasse et al. (1996) e Silva (1998), estudando E.grandis, encontraram diferenças significativas nos DC das mudas submetidas a manejos hídricos diferenciados. Nos trabalhos com clones, quanto maior o estresse aplicado, menor o DC (SASSE et al., 1996). Nos trabalhos com sementes, apesar de ter havido diferença significativa entre os níveis de estresse, não houve essa tendência (SILVA, 1998).

Pela análise de regressão apresentada na Figura 3 , verificou-se que houve correlação entre as irrigações aplicadas e a relação altura/diâmetro (H:D) das mudas em ambos os substratos, com a ressalva de que a relação aumentou à medida que se elevou a lâmina, em proporções praticamente constantes. Segundo Carneiro (1995), essa relação que exprime a qualidade de mudas em qualquer estádio do seu desenvolvimento deve situar-se entre os limites de 5,4 a 8,1, e, assim, somente sob $8 \mathrm{~mm}$ diários de água a relação estaria adequada. Trigueiro e Guerrini (2003), em mudas de eucalipto produzidas em substratos com diferentes proporções de biossólido, encontraram índices um pouco mais elevados, próximos a 12, que foram obtidos nesta pesquisa sob 12 e 14 $\mathrm{mm}$ diários de água para ambos os substratos.

Conforme as análises de regressão apresentadas na Figura 4, houve correlação entre as lâminas de irrigação aplicadas e o número de pares de folhas nas mudas (NPF), em ambos os substratos, com a ressalva de que no substrato CATV o NPF aumentou até $10 \mathrm{~mm}$ $\mathrm{dia}^{-1}$; a partir dessa lâmina de irrigação, diminuiu gradativamente e no substrato CPV, cujo NPF foi maior do que o obtido no substrato CATV, aumentou à medida que a lâmina de irrigação foi maior. Essa característica normalmente não é avaliada nas pesquisas científicas, já que em geral se avalia a área foliar; porém, em se tratando de manejo hídrico, é esperado que tanto a área das folhas diminua em função do estresse hídrico, bem como o número de folhas, como foi o caso desta pesquisa, em que se verificou que, sob 6 e $8 \mathrm{~mm}$ de irrigação diária, a sobrevivência final das mudas foi muito elevada em todos os substratos testados (LOPES et al., 2005). Com relação à área foliar, à medida que a quantia de água fornecida aumentou, maiores foram os aumentos em ambos os substratos; porém, foram maiores em CPV (Figura 5), talvez devido à maior capacidade de retenção de água desse substrato em relação à CATV. Outros pesquisadores, estudando manejo hídrico em mudas de eucalipto, também verificaram aumento de área foliar associado à maior disponibilidade de água, como foi o caso de Silva (1998) e de Ismael (2001).

R. Árvore, Viçosa-MG, v.31, n.5, p.835-843, 2007 


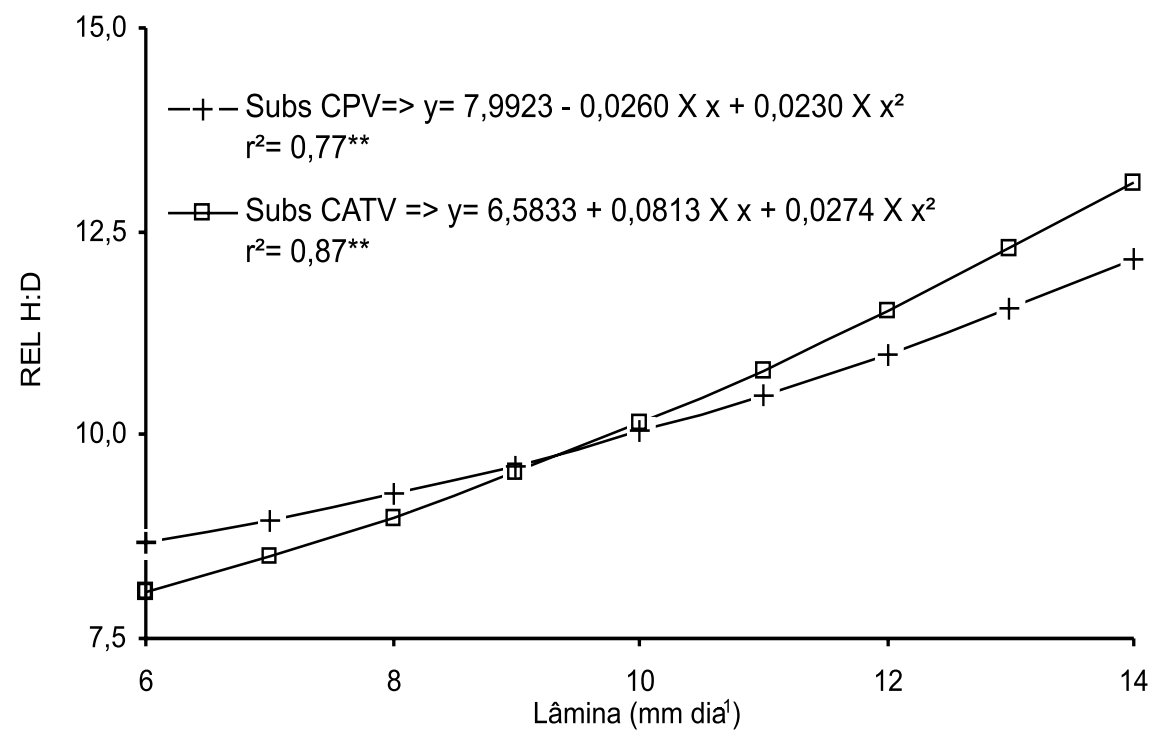

Figura 3 - Relação H:D das mudas de E. grandis, ao final do ciclo, sob diferentes lâminas de irrigação. Figure $3-H: D$ relation of E. grandis seedlings at the end of the cycle under different irrigation depths.

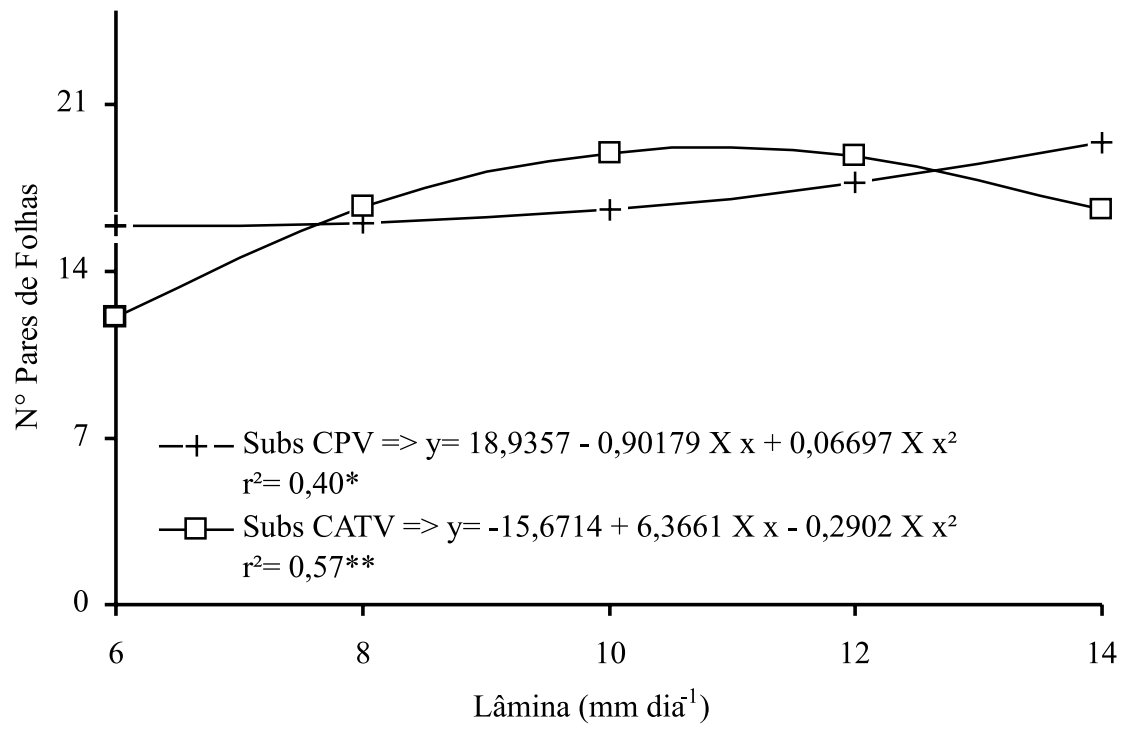

Figura 4 - Número de pares de folhas de mudas de E. grandis ao final do ciclo, sob diferentes lâminas de irrigação. Figure 4-Number of leaf pairs of E. grandis seedlings at the end of the cycle under different irrigation depths.

O regime hídrico influenciou o desenvolvimento radicial, conforme a análise de regressão apresentada na Figura 6. Ocorreu aumento gradativo em ambos os substratos, à medida que a lâmina de irrigação foi maior. Do mesmo modo, Alvarenga et al. (1994) encontraram valores proporcionais à quantidade de água aplicada para MSR de mudas de E. grandis. Trigueiro e Guerrini (2003) observaram que a MSR foi influenciada pela composição dos substratos testados, e em Multiplant ${ }^{\circledR}$ ocorreu maior incremento de raízes em relação àqueles compostos por diferentes doses de biossólido. Já Ismael (2001) observou que a MSR não diferiu nos substratos com potenciais entre $-0,05 \mathrm{e}-1,5 \mathrm{MPa}$.

Com relação ao desenvolvimento da parte aérea, o incremento de matéria seca (MSA) em ambos os substratos ocorreu conforme o aumento da lâmina (Figura

R. Árvore, Viçosa-MG, v.31, n.5, p.835-843, 2007 
7). A MSA em CATV (1,18 g) foi praticamente igual àquela obtida em CPV $(1,17 \mathrm{~g})$ sob $14 \mathrm{~mm} \mathrm{dia}^{-1}$, apesar de ter sido menor sob as demais lâminas testadas (principalmente sob 6, 8 e $10 \mathrm{~mm} \mathrm{dia}^{-1}$ ). Trigueiro e Guerrini (2003) observaram que, do mesmo modo que a MSR, a MSA foi influenciada pelos substratos, sendo superior para Multiplant $\AA$, possivelmente pela maior capacidade de retenção de água desse substrato em relação aos demais, afetando negativamente o desenvolvimento das mudas de eucalipto.

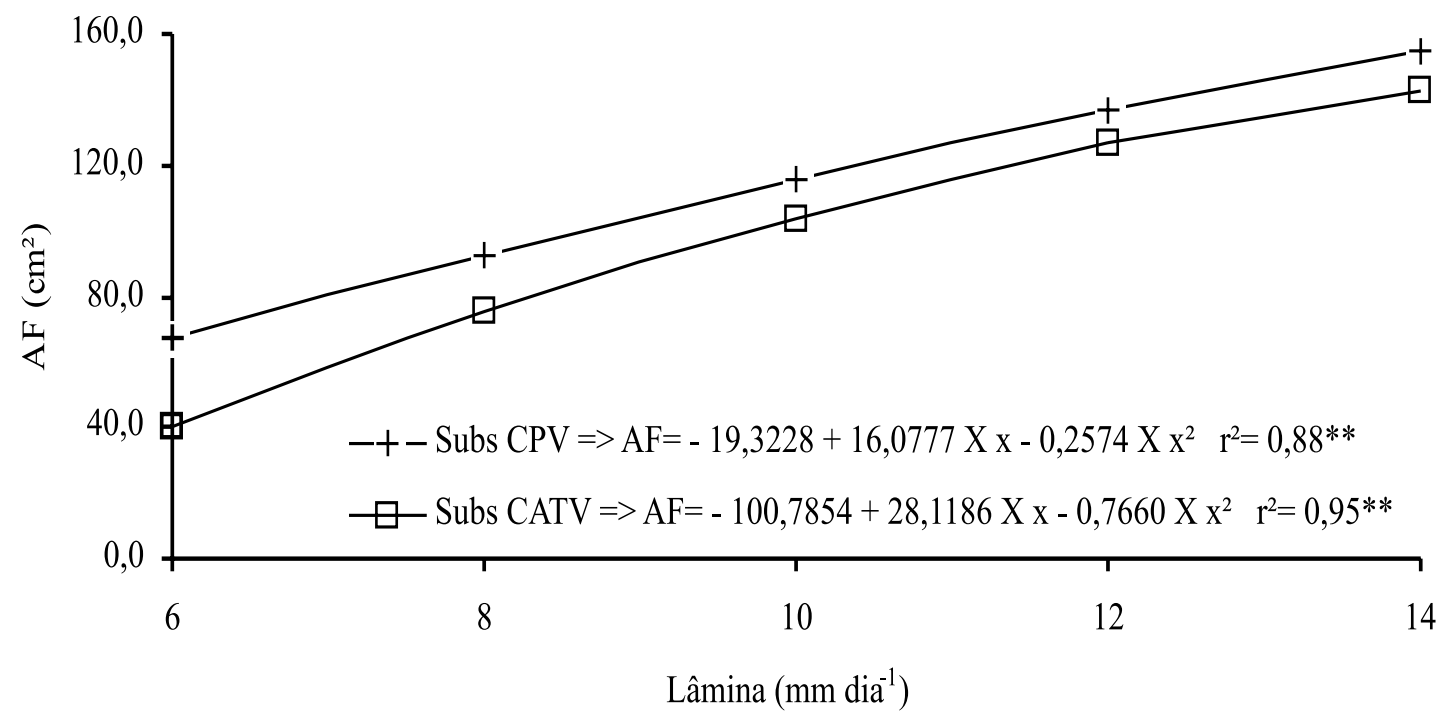

Figura 5 - Área foliar das mudas de E. grandis ao final do ciclo, sob diferentes lâminas de irrigação. Figure 5 - Leaf area of E. grandis seedlings of at the end of the cycle under different irrigation depths.

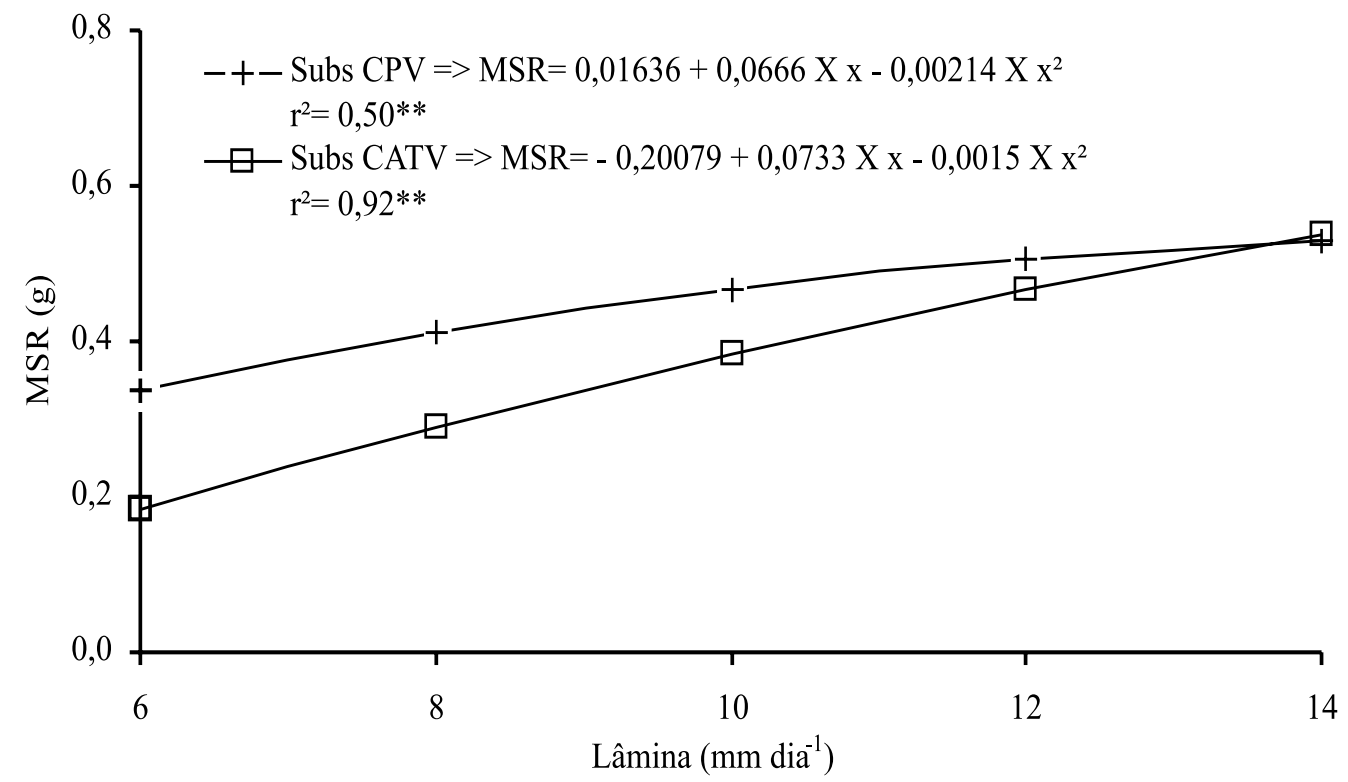

Figura 6 - Matéria seca de raízes das mudas de E. grandis ao final do ciclo, sob diferentes lâminas de irrigação. Figure 6 -Root dry matter of E. grandis seedlings at the end of the cycle under different irrigation depths. 


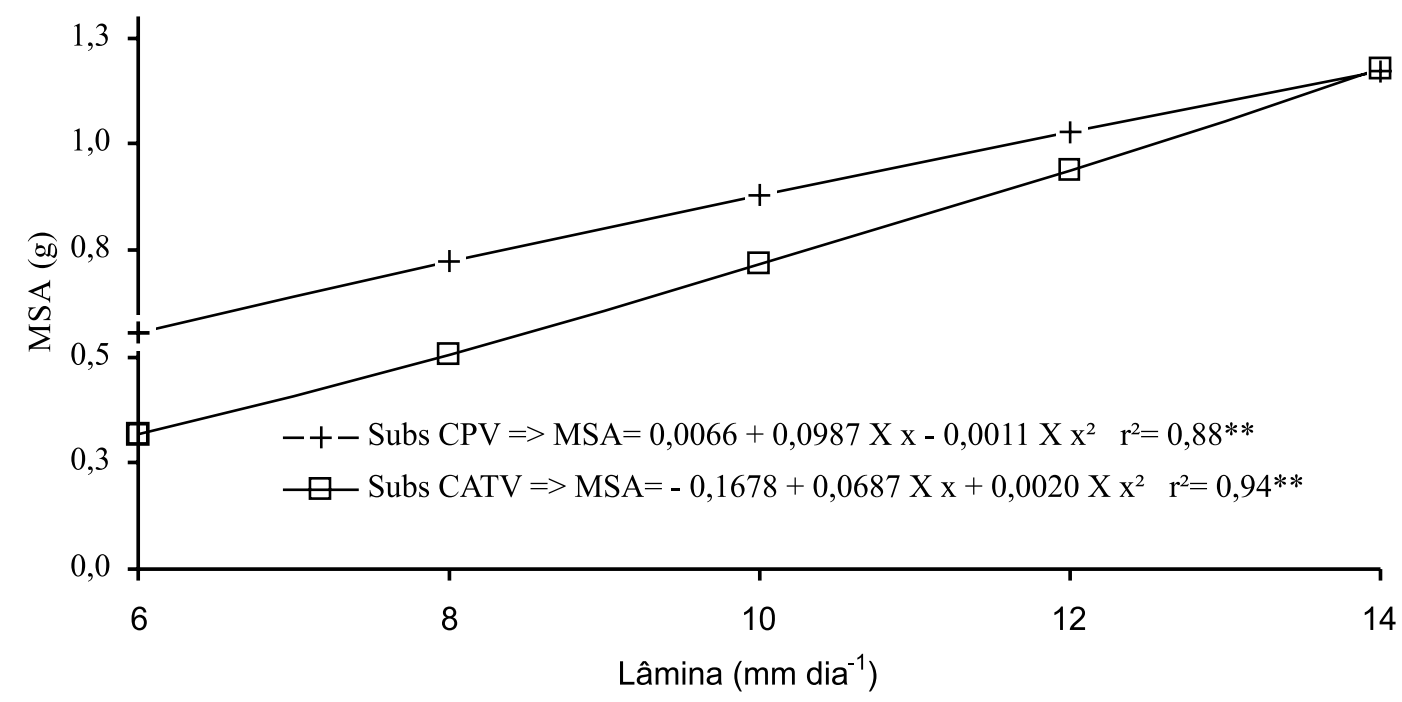

Figura 7 - Matéria seca da parte aérea das mudas de E. grandis ao final do ciclo, sob diferentes lâminas de irrigação. Figure 7 - Dry matter of aerial part of E. grandis seedlings at the end of the cycle under different irrigation depths.

\section{CONCLUSÕES}

Com base nos resultados, foi possível concluir que:

$\rightarrow$ As lâminas de irrigação brutas de 12 e de 14 $\mathrm{mm} \mathrm{dia}^{-1}$ foram as que mais contribuíram para o desenvolvimento das mudas de E. grandis com ótima qualidade aos 108 DAS.

$\rightarrow$ Todas as características morfológicas avaliadas foram influenciadas pelos substratos e pelas lâminas de irrigação aplicadas.

\section{AGRADECIMENTOS}

À Camará-Mudas Florestais, à FCA-UNESP e ao CNPq, pelos apoios recebidos.

\section{REFERÊNCIAS}

ABREU, M. F.; ABREU, C. A.; BATAGLIA, O. C. Uso da análise química na avaliação da qualidade de substratos e componentes. Campinas, Instituto Agronômico, 2002.p.17-28. (Documentos do Instituto Agronômico, 70)

ALVARENGA, R. C. et al. Efeitos do conteúdo de água no solo e da poda de raízes sobre o crescimento de mudas de eucalipto. Revista Árvore, v.18, n.2, p.107-114, 1994.

R. Árvore, Viçosa-MG, v.31, n.5, p.835-843, 2007
ANSORENA MINER, J. Sustratos:

propiedades y caracterización. Madrid: MundiPrensa, 1994. 172p.

BRASIL. Ministério da Agricultura. Análise de corretivos, fertilizantes e inoculantes. Métodos oficiais. Brasília: 1988. 110p.

CARVAlHO, C. M.; SILVA, C. R.

Determinação das propriedades físicas de substrato. Notas de aulas práticas. Botucatu: Universidade Estadual Paulista, 1992. 6p.

CARneiro, J. G. A. Produção e controle de mudas florestais. Viçosa: Folha de Viçosa, 1995. 451p.

CHAVES, J. H. et al. Seleção precoce de clones de eucalipto para ambientes com disponibilidade diferenciada de água no solo: Relações hídricas de plantas em tubetes. Revista Árvore, v.28, p.333-341, 2004.

COSTA, P. C. Produção do tomateiro em diferentes substratos. 2003. $119 \mathrm{f}$. Tese (Doutorado em Produção Vegetal Horticultura) -Universidade Estadual Paulista, Botucatu, 2003. 
GERVÁSIO, E. S. Efeito de lâminas de irrigação e doses de condicionador, associadas a diferentes tamanhos de tubetes, na produção de mudas de cafeeiro. 2003. 105f. Tese (Doutorado em Irrigação e Drenagem), Escola Superior de Agricultura Luiz de Queiroz, Piracicaba, 2003.

GOMES, J. M.; PAIVA, H. N.; COUTO, L. Produção de mudas de eucalipto. Informe Agropecuário, v.18, n.185, p.15-22, 1996.

GONÇALVES, J.L.M.; POGGIANI, F. Substratos para produção de mudas florestais. In: CONGRESSO LATINO AMERICANO DE CIÊNCIA DO SOLO, 13., 1996, Águas de Lindóia. Resumos... Piracicaba: Sociedade Latino Americana de Ciência do Solo, 1996. CD-ROM.

ISMAEL, J. J. Efeitos da fertilização nitrogenada e da umidade do substrato na aclimatação e na adaptação no campo de mudas de Eucalyptus grandis W. (HILL ex MAIDEN). 2001. 106f. Tese (Doutorado em Produção Vegetal) - Universidade Estadual Paulista, Jaboticabal, 2001.

LOPES, J. L. W. Produção de mudas de Eucalyptus grandis W. (Hill ex. Maiden) em diferentes substratos e lâminas de irrigação. 2004. 100f. Dissertação (Mestrado em Irrigação e Drenagem) - Universidade Estadual Paulista, Botucatu, 2004.

LOPES, J. L. W. et al. Efeitos da irrigação na sobrevivência, transpiração e no teor relativo de água na folha em mudas de Eucalyptus grandis em diferentes substratos. Scientia Forestalis, v.68, p.97-106, 2005.

RAWAT, P. S.; GUPTA, B. B.; RAWAT, J. S. Transpiration as affected by soil moisture in Eucalyptus tereticornis seedlings. Indian Forester, v.110, n.1, p.35-39, 1985.
SASSE, J. et al. Comparative responses of cuttings and seedlings of Eucalyptus grandis and Eucalyptus globulus to water stress. Tree Physiology, v.16, p.287-294, 1996.

SILVA, M. R. Caracterizações morfológica, fisiológica e nutricional de mudas de Eucalyptus grandis W. (HILL ex MAIDEN) submetidas a diferentes níveis de estresse hídrico durante a fase de rustificação. 1998. 105 f. Dissertação (Mestrado em Ciências Agrárias ) - Universidade Federal do Paraná, Curitiba, 1998.

SILVA, M. R. Efeitos do manejo hídrico e da aplicação de potássio na qualidade de mudas de Eucalyptus grandis W. (Hill ex. Maiden). 2003. 100f. Tese (Doutorado em Irrigação e Drenagem) -Universidade Estadual Paulista, Botucatu, 2003.

SILVA, M. R.; KLAR, A..; PASSOS, J. R. Efeitos do manejo hídrico e da aplicação de potássio nas características morfofisiológicas de mudas de Eucalyptus grandis W (Hill ex. Maiden). Irriga, v.9, n.1, p.31-40, 2004.

StURION, J. A. Métodos de produção e técnicas de manejo que influenciam o padrão de qualidade de mudas de essências florestais. Curitiba: Unidade Regional de Pesquisa Florestal Centro - Sul, 1981. 33p. (Apostila).

TRIGUEIRO, R. M.; GUERRINI, I. A. Uso de biossólidos como substrato para produção de mudas de eucalipto. Scientia Forestalis, n.64, p.150-162, 2003.

WENDLING, I.; GATTO, A. Substratos, adubação e irrigação na produção de mudas. Viçosa, MG: Aprenda Fácil, 2002. 166p. 